\title{
Ameliorative Effects of Thymoquinone on Sperm Parameters and Testosterone Level of Nicotine-Treated Sprague Dawley Rats
}

\section{Farah Dayana Rosli ${ }^{1}$}

https://orcid.org/0000-0002-3876-0203

Noor Hashida Hashim ${ }^{2^{*}}$

https://orcid.org/0000-0003-2572-4083

\section{Khairul Osman ${ }^{3}$}

https://orcid.org/0000-0003-3348-0672

\section{Siti Fatimah Ibrahim ${ }^{4}$}

https://orcid.org/0000-0002-4474-8032

\author{
Nurul Kabir ${ }^{5}$ \\ https://orcid.org/0000-0003-4735-4028
}

\begin{abstract}
${ }^{1}$ University of Malaya, Institute for Advanced Studies, Kuala Lumpur, Malaysia; ${ }^{2}$ University of Malaya, Center for Foundation Studies in Science, Biology Division, Kuala Lumpur, Malaysia; ${ }^{3}$ National University of Malaysia, Faculty of Allied Health Sciences, Kuala Lumpur, Malaysia; ${ }^{4}$ National University of Malaysia, Faculty of Medicine, Kuala Lumpur, Malaysia; ${ }^{5}$ University of Malaya, Faculty of Science, Institute of Biological Sciences, Kuala Lumpur, Malaysia.
\end{abstract}

Received: 2018.01.26; Accepted: 2019.06.16.

* Correspondence: nhhpasum@um.edu.my; Tel.: +603-79674629 (N.H.H.)

\section{HIGHLIGHTS}

- Nicotine negatively affected sperm count, membrane, mitochondria and testosterone level.

- Thymoquinone treatment improved sperm quality and testosterone level against nicotine.

\begin{abstract}
Thymoquinone (TQ), the main constituent of the volatile oil derived from Nigella sativa has shown pharmacological benefits against various diseases while nicotine is an active component in cigarette that is known to be detrimental. This study was conducted to assess the ameliorating effects of $\mathrm{TQ}$ on sperm count, membrane, mitochondria and testosterone of nicotine-treated rats. Rats were randomized into four groups: control, nicotine, TQ, and nicotine with TQ. Nicotine (5 mg/kg bwt/day) was subcutaneously injected for 30 days to induce damaging effects on sperm and testosterone level. Rats were
\end{abstract}


force-fed with TQ ( $5 \mathrm{mg} / \mathrm{kg}$ bwt/day) for the following 30 days. Sperm count was reduced in the nicotine group $(26.72 \pm 1.64106 / \mathrm{mL})$ but showed a significantly higher number in the nicotine $+\mathrm{TQ}$ group $(30.97 \pm 0.88106 / \mathrm{mL} ; \mathrm{p}<0.05)$. Results of sperm membrane integrity test and number of MitoTracker positive sperm also showed a significantly lower percentage in the nicotine group (47.34 $\pm 0.69 \%$ and $75.68 \pm 0.90 \%$, respectively) but a notable improvement in the nicotine+TQ group (52.58 $\pm 1.14 \%$ and $79.08 \pm 0.74 \%$, respectively). Testosterone concentration showed elevation in the nicotine+TQ group (7.61 $\pm 0.51 \mathrm{ng} / \mathrm{mL})$ compared to the nicotine group $(5.71 \pm 0.15 \mathrm{ng} / \mathrm{mL})$. TQ demonstrated ameliorative potential against the detrimental effects of nicotine towards sperm count, membrane, mitochondria and testosterone level.

Keywords: Thymoquinone; nicotine; rat sperm; membrane; mitochondria; testosterone.

\section{INTRODUCTION}

Infertility is a worldwide health issue that affects approximately $10 \%-15 \%$ of couples trying to conceive [1], and male factor infertility accounts for almost half of the cases [2]. Male infertility is any condition which adversely affects the chances of initiating a pregnancy with a female partner. Typically, those problems occur when man is unable to produce or deliver complete functioning sperm [3].

Cigarette smoking as a global phenomenon is recognized as a risk factor for many notable diseases. Cigarette smoking has been reported to have damaging effects on the male reproductive function that could eventually lead to infertility. Previous researches [4-6] has established that cigarette smoke causes deleterious effects on sperm count, kinetic parameters, morphology and DNA/chromatin integrity. The adverse effects of cigarette on fertility could be attributed to its content which includes several toxic chemicals, mutagens and carcinogens with the primary psychoactive component being nicotine $[7,8]$. Nicotine is revealed to have unfavorable results towards the reproductive function particularly in males [9]. Therefore, there is an ongoing search for an ideal curative substance against the deleterious effects of nicotine particularly on reproductive health.

Among many medicinal plants, Nigella sativa (NS) is a medicinally promising herb which has been researched upon and well-known for its pharmacological benefits. Thymoquinone (TQ) is the biologically active compound of NS seed and the largest constituent of its volatile oil [10]. Thymoquinone can be found in many other medicinal plants such as Monarda fistulosa and Juniperus [11]. Nigella sativa (NS) is the TQ source that is most widely studied and reported to exhibit pharmacological benefits for a varied range of pathological conditions [12] and received particular consideration and has been extensively looked into for its therapeutic properties.

A review paper on TQ's therapeutic potentials showed that TQ has beneficial medicinal effects in various areas such as antibacterial [13], anti-inflammatory [14], anxiety modulatory [15], and anticancer activities [16]. It has been reported to possess strong antioxidant properties and oral administration of $\mathrm{TQ}$ is capable of protecting several organs against oxidative damage $[17,18]$. In the reproductive studies, TQ demonstrated significant improvement of semen quality and reproductive characteristics in mice [19]. However, the role of TQ against nicotine effects has not been studied so far. Therefore, the aim of the present study was to investigate the possible ameliorative role of TQ on sperm quality of nicotine-treated rats. 


\section{MATERIAL AND METHODS}

\section{Animals}

The experimental animals were thirty two healthy adult male Sprague Dawley rats (7 - 9 weeks), weighing $200-250 \mathrm{~g}$. The rats were reared in an animal house located at the Centre for Foundation Studies in Science. Prior to the commencement of treatment, rats were acclimatized to the experimental condition for one week. The animals were maintained at room temperature under standard condition of $12: 12 \mathrm{~h}$ light-dark cycles. The food was in the form of dry chow pellets and water was available ad libitum throughout the experimental period. The study design was reviewed and approved by the Institute of Graduate Studies and Institutional Animal Care and Use Committee (IACUC), Universiti Malaya. The experiments were conducted in accordance with the guidelines of the IACUC [PASUM/30/12/2015/FDR (R)].

\section{Experimental design}

Rats were randomly assigned into four groups (Table 1): Control group was administered with normal saline through oral gavage for 60 days. The nicotine group was subcutaneously (s.c.) injected with $5 \mathrm{mg} / \mathrm{kg}$ bwt nicotine for 30 days, followed by normal saline via oral gavage for the next 30 days. The TQ group was fed with normal saline through oral gavage for 30 days, followed by oral administration of TQ ( $5 \mathrm{mg} / \mathrm{kg} \mathrm{bwt} / \mathrm{day})$ for the next 30 days. The nicotine+TQ group was injected with $5 \mathrm{mg} / \mathrm{kg} \mathrm{bwt} / \mathrm{day}$ nicotine (s.c.) for 30 days, followed by administration of TQ ( $5 \mathrm{mg} / \mathrm{kg}$ bwt/day) by oral gavage for 30 days.

Thymoquinone ( $\geq 98 \%$ pure) was purchased from Sigma-Aldrich, (St. Louis, Missouri) while nicotine (L-nicotine, 99+\%, CAS RN: 54-11-5) was purchased from Acros Organics, (New Jersey, USA). Rats were euthanized on day 61 by intraperitonial injection of ketamine-xylazine (10:1).

Blood sample was collected into serum separator tubes through cardiac puncture. The blood was left at room temperature to clot after which it was centrifuged at $4^{\circ} \mathrm{C}$ for 10 minutes at $3000 \mathrm{rpm}$. Serum was then transferred to micro-centrifuge tubes and stored at $-20^{\circ} \mathrm{C}$ for hormone assay. Cauda epididymis were excised from each rat, cut open and placed in a tube containing $1 \mathrm{~mL}$ of Toyoda-Yokoyama-Hoshi $(\mathrm{TYH})$ medium. The tube was placed in a $\mathrm{CO}^{2}$ incubator with $5 \% \mathrm{CO}^{2}$ for 30 minutes to allow sperm swim up. The excess tissues were then discarded out of the tubes prior to sperm evaluation.

\section{Sperm count}

Sperm concentration was determined using by a Makler Counting Chamber (Sefi-Medical Instruments Ltd., Haifa, Israel). A sperm suspension of $10 \mu \mathrm{L}$ was placed onto the Makler Chamber stage and counted for the number of sperm under a light microscope (Olympus, Japan) [20].

\section{Sperm membrane integrity}

The hypo-osmotic swelling test (HOST) was used to evaluate the functional integrity of the sperm membrane based on the presence of coiled or swollen tails (HOST positive), which indicated sperm with intact cell membrane. The test was performed by incubating 50 $\mu \mathrm{L}$ of sperm suspension with $500 \mu \mathrm{L}$ of $150 \mathrm{mOsm} / \mathrm{L}$ hypo-osmotic solution $(7.35 \mathrm{~g}$ of sodium citrate $\left(\mathrm{C}_{6} \mathrm{H}_{5} \mathrm{Na}_{3} \mathrm{O}_{7} .2 \mathrm{H}_{2} \mathrm{O}\right)$ and $13.51 \mathrm{~g}$ fructose in $1000 \mathrm{~mL}$ of distilled water) at $37^{\circ} \mathrm{C}$ for 45 minutes [21]. After incubation, $10 \mu \mathrm{L}$ of the mixture was smeared on to a slide and air dried. Slides were stained with Diff-Quick stain (Dade Behring Inc., Newark, DE) and rinsed until it was clear. Two hundred sperm per sample were counted under a light microscope (Olympus, Japan) at 40X magnification and the number of HOST positive sperm was recorded. 


\begin{tabular}{ll}
\hline \multicolumn{1}{c}{ Treatment Group } & \multicolumn{1}{c}{ Dosage } \\
\hline Control & $0.9 \% \quad$ (p.o.) \\
Nicotine & $5 \mathrm{mg} / \mathrm{kg} \mathrm{bwt} \mathrm{(s.c.)}$ \\
Thymoquinone (TQ) & $5 \mathrm{mg} / \mathrm{kg} \mathrm{bwt} \mathrm{(p.o.)}$ \\
Nicotine + Thymoquinone (TQ) & $5 \mathrm{mg} / \mathrm{kg}$ bwt (s.c.) \& $5 \mathrm{mg} / \mathrm{kg}$ bwt (p.o.)
\end{tabular}

Table 1 - Treatment and dosage for each group of rats.

\section{Mitochondria assessment using MitoTracker Red FM}

MitoTracker Red FM (Molecular Probes, Eugene, Oregon, USA), a mitochondrion-specific vital dye was used to assess the sperm mitochondrial function as it labeled active mitochondria utilizing its membrane potential. Live sperm suspension $(1 \times 106$ sperm $/ \mathrm{mL}$ ) were incubated with $500 \mathrm{nM}$ MitoTracker RedFM and $5 \mu \mathrm{L}$ of $200 \mu \mathrm{g} / \mathrm{mL}$ 4',6-diamidino-2-phenylindole, (DAPI) (Molecular Probes, Eugene, Oregon, USA) for nuclear counterstain at $37^{\circ} \mathrm{C}$ for 30 minutes. Subsequently, the sperm were washed and resuspended in fresh pre-warmed medium. Samples were then mounted on a microscope slide and examined under fluorescent microscope (Carl Zeiss, Göttingen, Germany). The percentage of MitoTracker positive sperm was determined by counting 200 sperm per sample [22].

\section{Testosterone assay}

Testosterone was measured using a commercially available kit (IBL, Hamburg, Germany) in accordance with the manufacturer's instructions. The kit utilizes a solid phased enzyme-linked immunosorbent assay (ELISA) based on the competition principle. Samples were plated in triplicates and each testosterone concentration was calculated from a standard curve with 5 standard values. The optical density of the samples and testosterone standards were measured at $450 \mathrm{~nm}$ using a microplate reader (Tecan Infinite M1000 Pro, Männedorf, Switzerland).

\section{Statistical analysis}

Data analyses were conducted using the SPSS 23.0 software and values were expressed as mean \pm S.E. The data among the treatment groups were analyzed using the Analysis of Variance (ANOVA) and Duncan Multiple Range Test (Duncan-MRT) with a statistical significant level of $p<0.05$.

\section{RESULTS}

\section{Effect of TQ on sperm parameters}

The sperm count significantly decreased $(p<0.05)$ in the nicotine group $(26.72 \pm 1.64$ $106 / \mathrm{mL})$ in comparison to control $(31.75 \pm 0.80106 / \mathrm{mL})$. However, the number of sperm increased significantly in the nicotine+TQ group $(30.97 \pm 0.88106 / \mathrm{mL}$ ) (Table 2). The membrane integrity of the sperm was represented by the percentage of HOST positive cells, exhibiting tail coiling (Figure 1). As anticipated, there was a significant reduction $(p<0.05)$ of intact sperm membrane in the nicotine group (47.34 $\pm 0.69 \%)$ compared to the control $(65.98 \pm 1.03 \%)$. The percentage of membrane integrity notably increased in the nicotine + TQ group $(52.58 \pm 1.14 \%$ ) (Table 2$)$. The percentage of sperm showing 
MitoTracker Red FM fluorescence was significantly higher $(p<0.05)$ in the control $(87.04 \pm$ $0.88 \%)$ and nicotine + TQ $(79.08 \pm 0.74 \%)$ groups compared to the nicotine group $(75.68 \pm$ 0.90) (Figure 2 and 3).

\section{Effect of TQ on testosterone level}

The testosterone concentration (Table 2$)$ in the nicotine $(5.71 \pm 0.15 \mathrm{ng} / \mathrm{mL}$ ) group was significantly lower $(p<0.05)$ than that of the control $(8.45 \pm 0.36 \mathrm{ng} / \mathrm{mL})$ and TQ $(8.89 \pm 0.30$ $\mathrm{ng} / \mathrm{mL}$ ) groups. The nicotine+TQ group also demonstrated an elevated concentration of testosterone $(7.61 \pm 0.51 \mathrm{ng} / \mathrm{mL})$ compared to the nicotine group.

Table 2 - Sperm count, percentages of HOST positive sperm and testosterone levels of rats treated with nicotine and thymoquinone.

\begin{tabular}{cccc}
\hline $\begin{array}{c}\text { Parameter } \\
\text { Group }\end{array}$ & $\begin{array}{c}\text { Sperm Count } \\
1 \times 10^{6} / \mathrm{ml}\end{array}$ & $\begin{array}{c}\text { HOST \% } \\
\text { (Mean } \pm \text { S.E.) }\end{array}$ & $\begin{array}{c}\text { Testosterone } \mathrm{ng} / \mathrm{ml} \\
\text { (Mean } \pm \text { S.E.) }\end{array}$ \\
& (Mean \pm S.E.) & & \\
\hline
\end{tabular}
Control
$31.75 \pm 0.80^{\mathrm{b}}$
$65.98 \pm 1.03^{c}$
$8.45 \pm 0.36^{b, c}$

Nicotine

$26.72 \pm 1.64^{a}$

$47.34 \pm 0.69^{a}$

$5.71 \pm 0.15^{a}$

Thymoquinone (TQ)

$31.28 \pm 1.12^{b}$

$54.61 \pm 1.16^{\mathrm{b}}$

$8.89 \pm 0.30^{\circ}$

\begin{tabular}{|c|c|c|c|}
\hline $\begin{array}{l}\text { Nicotine + Thymoquinone } \\
\text { (TQ) }\end{array}$ & $30.97 \pm 0.88^{b}$ & $52.58 \pm 1.14^{b}$ & $7.61 \pm 0.51^{b}$ \\
\hline
\end{tabular}

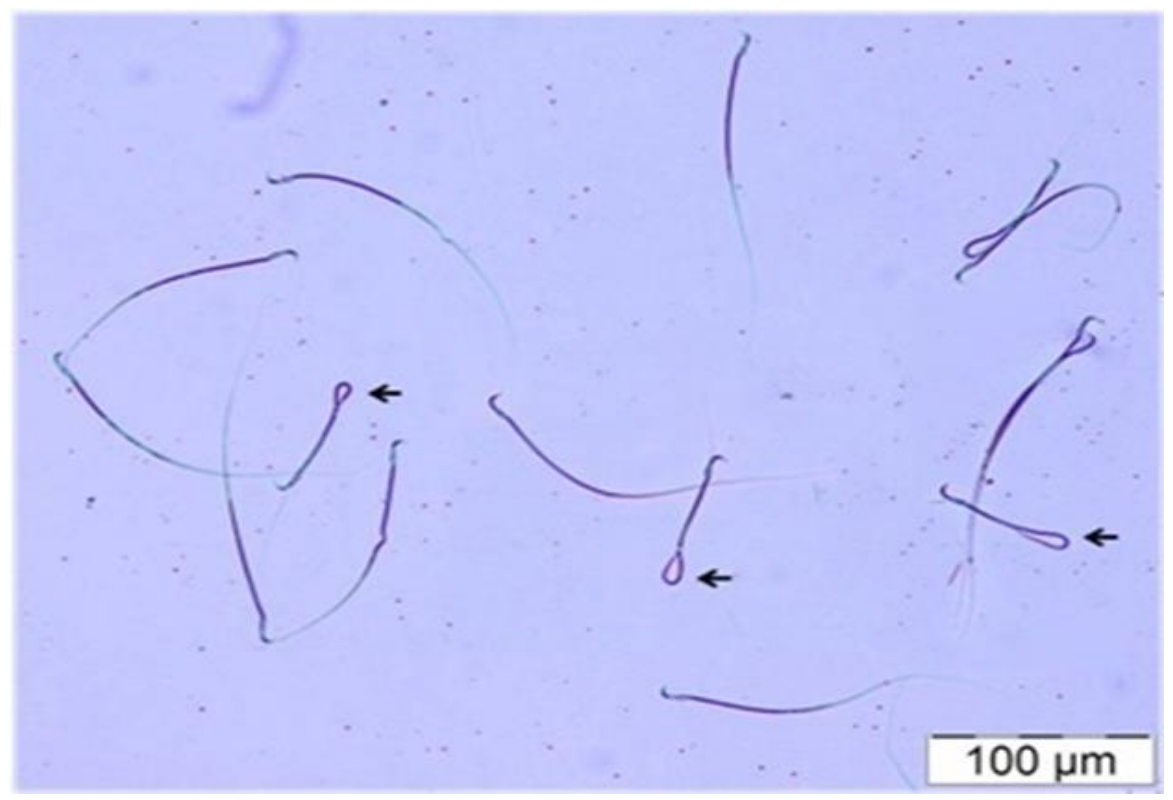

Figure 1 - Photomicrograph of rat sperm after exposure to hypo-osmotic solution in the Hypo-Osmotic Swelling Test (HOST). Sperm with intact membrane or HOST positive exhibited tail coiling (arrowheads). Samples were observed under a light microscope (Olympus, Japan) at 40X magnification. 
Rosli, F.D.; et al.

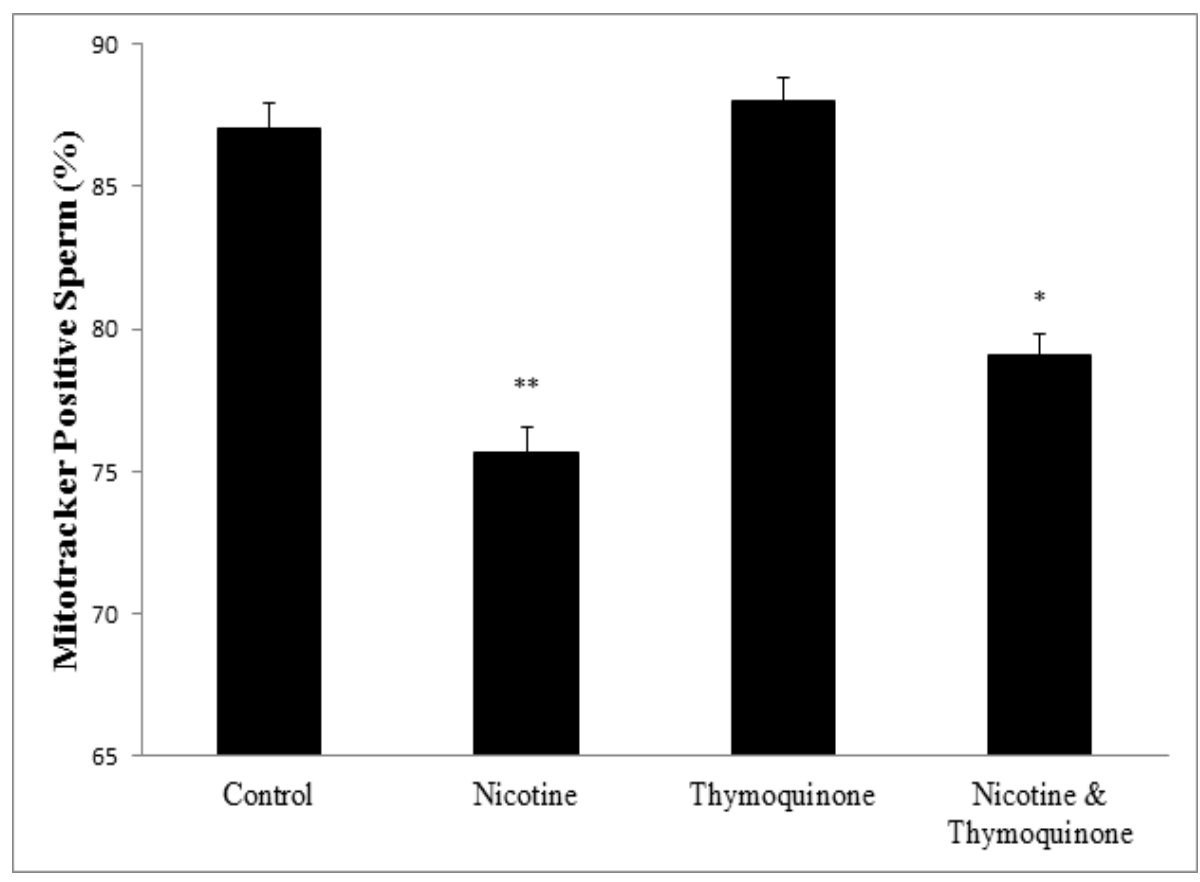

Figure 2 - Sperm mitochondrial assessment using MitoTracker Red FM. Histogram of the percentage of sperm stained with MitoTracker in different groups. Data is expressed as mean $\pm S$.E with $n=8$ in each group. *Significantly different compared to the control group. ${ }^{* *}$ Significantly different compared to the control and nicotine+thymoquinone group $(p<0.05)$.

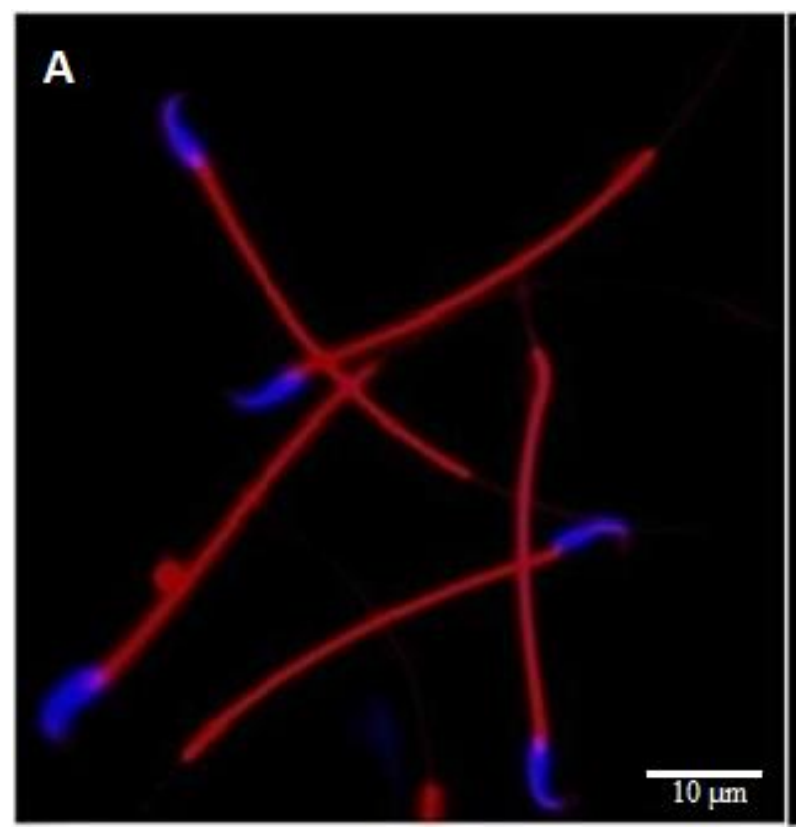

(a)

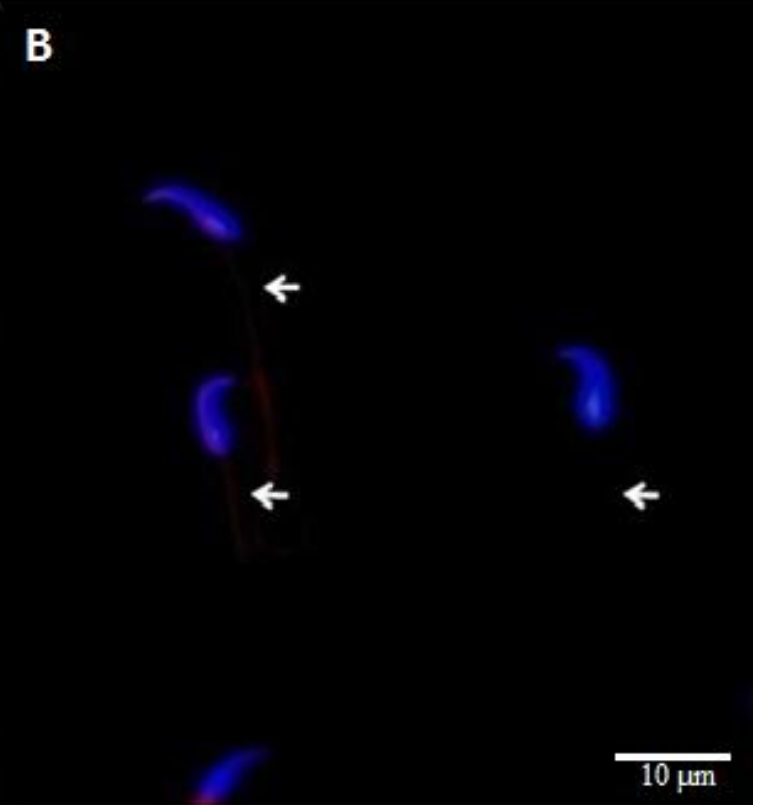

(b)

Figure 3 - Photomicrograph of rat sperm stained with MitoTracker Red FM. (a) MiTotracker positive sperm stained mitochondria in red at the middle piece region indicated active mitochondria activity. (b) MitoTracker negative sperm demonstrated severely reduced staining of mitochondria (arrowheads). For imaging purposes, nuclear DNA was stained with the DNA dye DAPI (blue). Samples were observed under fluorescent microscope (Carl Zeiss, Göttingen, Germany) at 40X magnification. 


\section{DISCUSSION}

Cigarette smoke contains unhealthy organic compounds and gases among which is nicotine, one of most abundant particle. Nicotine is responsible for various health problems and could play a role in male infertility through alteration of sperm characteristic [23]. In present study, a significant decrease in the sperm count of the nicotine-treated rats was detected as compared to the control group. This finding supported the adverse effects of nicotine towards sperm [24-26]. Reduced testosterone concentration was also recorded which was associated with the decreased in sperm count as shown in Table 2 . This is because testosterone plays a role in spermatogenesis in the testis and sperm maturation in the epididymis [27]. This is in agreement with previous report that suggested nicotine reduces testosterone production by its effects on nicotinic acetylcholine receptors through inhibition of selective enzyme activity required in androgen biosynthesis [28]. Moreover, nicotine could directly promote testicular tissue peroxidation through free radical generations that would interfere with spermatogenesis and steroidogenesis [25]. This is in accordance with the elevated levels of reactive oxygen species (ROS) in seminal fluids of smokers [29].

Thymoquinone, the main constituent of Nigella sativa seed oil has shown beneficial effects towards semen quality and reproductive function [19,30-31]. Those findings were similar to the current result that the sperm count and testosterone levels in nicotine-treated rats were significantly increased after the treatment of $T Q$. These are also consistent with a previous study that TQ had significantly improved the plasma testosterone level and epididymal sperm count caused by administration of lead [32]. In addition, several reports have shown that TQ plays a role to increase Leydig cell number and testosterone levels which eventually improved spermatogenesis [33,34]. Thymoquinone also exerts marked antioxidant characteristic which could ameliorate the spermatogenesis impairment caused by testicular injury through oxidative stress. A previous study demonstrated the protective effects of TQ on hampered spermatogenesis from chronic toluene exposure [35]. Another study has suggested that TQ could ameliorate the deleterious effects of cadmium chloride by activating testicular endocrine and antioxidant systems [31]. Its antioxidant defense against generation of reactive oxygen species (ROS) suggested its protective activity in the testicular tissue [36].

The plasma membrane of sperm is important in providing fluidity that is necessary in membrane fusion. The present study demonstrated a significant higher number of membrane damaged sperm among rats of the nicotine-treated group in comparison with other groups. This was indicated by the decline in percentage of HOST positive sperm. This result was in line with those of previous studies that showed smoking resulted in an increase in oxidative attack on sperm membrane [37-39] which could lead to initiation of the lipid peroxidation cascade [40]. Sperm are particularly vulnerable to oxidative damage due to the large amount of polyunsaturated fatty acids in the plasma membrane which are the substrates for ROS [41]. Constituents of cigarette such as nicotine are highly associated with an increase in ROS production [42] which decreases the antioxidant capacity of the seminal fluid [43]. Leukocyte is the main ROS producer of the seminal fluid and smoking could increase number of seminal leukocytes. Consequently, this might overwhelm the antioxidant defenses causing oxidative stress, which in turn would damage the lipid bilayer membrane $[44,45]$.

Notably, there was also a significant decline in the percentage of MitoTracker positive sperm among rats treated with nicotine compared to the other groups. This result was consistent with the previous data which demonstrated the adverse effects of cigarette smoke extract on sperm mitochondrial activity [5]. Mitochondria of sperm play a major role in supplying energy for motility. Significant increase of free radicals has been demonstrated to affect mitochondrial functions [41]. Direct ROS attack on the sperm mitochondria could result in decreased energy production, hence, impede sperm motility [46]. Earlier report showed that the mitochondria membrane potential (MMP) in sperm of infertile men was 
Rosli, F.D.; et al.

decreased with elevated ROS production [47], consequently, contributes to the loss in membrane integrity, impaired cell functions and sperm motility.

Thymoquinone has shown its potential to ameliorate the adverse effect of nicotine on sperm parameter as indicated by the significant increase in percentage of positive HOST sperm and notable improvement of MitoTracker positive sperm among rats treated with both nicotine and TQ. The effects could be attributed to TQ's potent antioxidant properties, its free radicals scavenging system and lipid peroxidation suppression, as well as its ability in sustaining the antioxidant defense mechanisms during free radical reactions $[48,49]$.

\section{CONCLUSION}

The present study demonstrated that administration of nicotine had altered the testosterone level and caused damaging effects toward sperm in terms of its concentration, membrane integrity and mitochondrial function. In conclusion, the administration of TQ could ameliorate the adverse effects of nicotine on male fertility. These make TQ a promising supplement in combating male infertility especially among smokers. Further study is needed to explore mechanism of action of TQ for its curative role against physiological and structural damages of the reproductive system caused by nicotine.

Funding: The project was funded by University Malaya Research Grant (no. UMRG-RG378/15AFR). Acknowledgments: Gratitude to Physiology Laboratory, Faculty of Medicine, National University of Malaysia, for technical support and usage of facilities.

Conflicts of Interest: The authors declare no conflict of interest. The funders had no role in the design of the study; in the collection, analyses, or interpretation of data; in the writing of the manuscript, or in the decision to publish the results.

\section{REFERENCES}

1. Boivin J, Bunting L, Collins JA, Nygren KG. International estimates of infertility prevalence and treatment-seeking: potential need and demand for infertility medical care. Hum Reprod. 2007; 22(6): 1506-1512.

2. Jarow JP, Sharlip ID, Belker AM, Lipshultz LI, Sigman M, Thomas AJ, et al. Best practice policies for male infertility. J Urol. 2002; 167(5): 2138-2144.

3. Agarwal A, Durairajanayagam D, Halabi J, Peng J, Vasquez-Levin M. Proteomics, oxidative stress and male infertility. Reprod Biomed Online. 2014; 29(1): 32-58.

4. Ali Jorsaraei SG, Shibahara H, Ayustawati, Hirano Y, Shiraishi Y, Khalatbari A, et al. The in-vitro effects of nicotine, cotinine and leptin on sperm parameters analyzed by CASA system. Int $J$ Reprod Biomed. 2008; 6(3): 157-165.

5. Calogero A, Polosa R, Perdichizzi A, Guarino F, La Vignera S, Scarfia A, et al. Cigarette smoke extract immobilizes human spermatozoa and induces sperm apoptosis. Reprod Biomed Online. 2009; 19(4): 564-571.

6. Sankako MK., Garcia PC, Piffer RC, Pereira OCM. Semen and reproductive parameters during some abstinence periods after cigarette smoke exposure in male rats. Braz Arch Biol Technol. 2013; 56(1): 93-100.

7. Colagar AH, Jorsaraee GA, Marzony ET. Cigarette smoking and the risk of male infertility. Pak J Biol Sci. 2007; 10(21): 3870-3874.

8. Harlev A, Agarwal A, Gunes SO, Shetty A, du Plessis SS. Smoking and male infertility: an evidence-based review. World J Mens Health. 2015; 33(3): 143-160. 
9. Asiyah HA, Syazana NS, Hashida NH, Durriyyah Sharifah HA, Kamaruddin MY. Effects of nicotine and gelam honey on testis parameters and sperm qualities of juvenile rats. Sci Res Essays. 2011; 6(26):5471-5474.

10. Darakhshan S, Pour AB, Colagar AH, Sisakhtnezhad S. Thymoquinone and its therapeutic potentials. Pharmacol Res. 2015; 95: 138-158.

11. Taborsky J, Kunt M, Kloucek P, Lachman J, Zeleny V, Kokoska L. Identification of potential sources of thymoquinone and related compounds in Asteraceae, Cupressaceae, Lamiaceae, and Ranunculaceae families. Open Chemistry. 2012; 10(6): 1899-1906.

12. Salem ML. Immunomodulatory and therapeutic properties of the Nigella sativa L. seed. Int Immunopharmacol. 2005; 5(13): 1749-1770.

13. Hannan A, Saleem S, Chaudhary S, Barkaat M, Arshad, MU. Anti-bacterial activity of Nigella sativa against clinical isolates of methicillin resistant Staphylococcus aureus. J Ayub Med Coll Abbottabad. 2008; 20(3): 72-74.

14. Nehar S, Kumari M. Protective effect of Nigella sativa seed oil on liver. An Quarterly Int J Envi Sci. 2012; 1 : 409-412.

15. Sayeed MSB, Shams T, Hossain SF, Rahman MR, Mostofa AGM, Kadir MF, et al. Nigella sativa L. seeds modulate mood, anxiety and cognition in healthy adolescent males. $J$ Ethnopharmacol. 2014; 152(1): 156-162.

16. Shoieb AM, Elgayyar M, Dudrick PS, Bell JL, Tithof PK. In vitro inhibition of growth and induction of apoptosis in cancer cell lines by thymoquinone. Int J Oncol. 2003; 22(1): 107-114.

17. Nagi MN, Mansour MA. Protective effect of thymoquinone against doxorubicin-induced cardiotoxicity in rats: A possible mechanism of protection. Pharmacol Res. 2000; 41(3): 283-289.

18. Mansour MA, Nagi MN, El-Khatib AS, Al-Bekairi AM. Effects of thymoquinone on antioxidant enzyme activities, lipid peroxidation and DT-diaphorase in different tissues of mice: a possible mechanism of action. Cell Biochem Funct. 2002; 20(2): 143-151.

19. Al-Zahrani S, Mohany M, Kandeal S, \& Badr G. Thymoquinone and vitamin E supplementation improve the reproductive characteristics of heat stressed male mice. J Med Plants Res. 2012; 6(3): 493-499.

20. Makler A. A new chamber for rapid sperm count and motility estimation. Fertil Steril. 1978; 30(3): 313-318.

21. Vaez A, Mardani M, Razavi S. Impact of saffron on rat sperm membrane integrity and spermatogenesis status. Adv Biomed Res. 2014;3.

22. Ramalho-Santos J, Amaral A, Sousa AP, Rodrigues AS, Martins L, Baptista M. Probing the structure and function of mammalian sperm using optical and fluorescence microscopy. Modern Research and Educational Topics in Microscopy. 2007; 1: 394-402.

23. Brčić Karačonji I. Facts about nicotine toxicity. Arh Hig Rada Toksikol. 2005; 56(4): 363-371.

24. Londonkar RL, Srinivasreddy P, Somanathreddy P, Patil SB. Nicotine induced inhibition of the activities of accessory reproductive ducts in male rats. J Ethnopharmacol. 1998; 60(3): 215-221.

25. Jana K, Samanta PK, De DK. Nicotine diminishes testicular gametogenesis, steroidogenesis, and steroidogenic acute regulatory protein expression in adult albino rats: Possible influence on pituitary gonadotropins and alteration of testicular antioxidant status. Toxicol Sci. 2010; 116(2): 647-659. 
26. Oyeyipo IP, Raji Y, Emikpe BO, Bolarinwa AF. Effects of nicotine on sperm characteristics and fertility profile in adult male rats: A possible role of cessation. J Reprod Infertil. 2011; 12(3): 201-207.

27. Sharpe RM, Maddocks S, Millar M, Saunders PTK, Kerr JB, McKinell C. Testosterone and spermatogenesis: Identification of stage dependent, androgen regulated proteins secreted by adult rat seminiferous tubule. J Androl. 1992; 13(2): 172-184.

28. Kasson BG, Hsueh AJ. Nicotinic cholinergic agonists inhibit androgen biosynthesis by cultured rat testicular cells. Endocrinol. 1985; 117(5): 1874-1880.

29. Tremellen K. Oxidative stress and male infertility - A clinical perspective. Hum Reprod Update. 2008; 14(3): 243-258.

30. Tawfeek F, Ahmed S, Soulaf J, Kakel S. Effect of Nigella sativa oil treatment on the sex organs and sperm characters in rats exposed to hydrogen peroxide. Mesopotamia J Agri. 2006; 34(1): 2-8.

31. Sayed MM, Hassanein KM, Senosy W. Protective effects of thymoquinone and I-cysteine on cadmium-induced reproductive toxicity in rats. Toxicol Reports. 2014; 1:612-620.

32. Mabrouk A, Ben Cheikh $H$. Thymoquinone supplementation ameliorates lead-induced testis function impairment in adult rats. Toxicol Ind Health. 2014; 32(6): 1114-1121.

33. Fouad AA, Albuali WH, Jresat I. Protective effect of thymoquinone against arsenic-induced testicular toxicity in rats. Int J Med Health Biomed Eng. 2014; 8(2): 92-95.

34. Aithal M, Haseena S, Das KK, Saheb SH. Effect of Nigella sativa seed and thymoquinone on reproductive parameters in sterptozotocine induced diabetic and normal male albino rats. Int $J$ Integ Med Sci. 2016; 3(3): 248-252.

35. Kanter $\mathrm{M}$. Thymoquinone reestablishes spermatogenesis after testicular injury caused by chronic toluene exposure in rats. Toxicol Ind Health. 2011; 27(2): 155-166.

36. Kamarzaman S, Sha'ban M, Rahman SA Rahman SA. Effects on mouse spermatogenesis and DNA fragmentation following exposure to cyclophosphamide and thymoquinone. European Int $J$ Sci Tech. 2013; 2(7): 119-136.

37. Vine MF. Smoking and male reproduction: a review. Int J Androl. 1996; 19(6): 323-337.

38. Kim JG, Parthasarathy S. Oxidation and the spermatozoa. Semin Reprod Endocrinol. 1998; 16(4): 235-239.

39. Saleh RA, Agarwal A, Sharma RK, Nelson DR, Thomas AJ. Effect of cigarette smoking on levels of seminal oxidative stress in infertile men: a prospective study. Fertil Steril. 2002; 78(3): 491-499.

40. Sharma R, Agarwal A. Role of reactive oxygen species in male infertility. Urol. 1996; 48(6): 835-850.

41. Agarwal A, Prabakaran SA. Oxidative stress and antioxidants in male infertility: A difficult balance. Iranian J Reprod Med. 2005; 3(1): 1-8.

42. Traber MG, Van Der Vliet A, Reznick AZ, Cross CE. Tobacco-related diseases: is there a role for antioxidant micronutrient supplementation? Clin Chest Med. 2000; 21(1): 173-187.

43. Kothari S, Thompson A, Agarwal A, du Plessis SS. Free radicals: their beneficial and detrimental effects on sperm function. Indian J Exp Biol. 2010; 48(5): 425-435.

44. Trummer $\mathrm{H}$, Habermann $\mathrm{H}$, Haas J, Pummer $\mathrm{K}$. The impact of cigarette smoking on human semen parameters and hormones. Hum Reprod. 2002; 17(6): 1554-1559.

45. Mostafa T. Cigarette smoking and male infertility. J Adv Res. 2010; 1(3): 179-186. 
46. De Lamirande E, Gagnon C. Reactive oxygen species and human spermatozoa. II. Depletion of adenosine triphosphate plays an important role in the inhibition of sperm motility. $J$ Androl. 1991; 13(5): 379-386.

47. Wang X, Sharma R, Gupta A, George V, Thomas A, Falcone T, Agarwal A. Alterations in mitochondria membrane potential and oxidative stress in infertile men: A prospective observational study. Fertil Steril. 2003; 80: 844-850.

48. Sankaranarayanan $C$, Pari L. Thymoquinone ameliorates chemical induced oxidative stress and B-cell damage in experimental hyperglycemic rats. Chem Biol Interact. 2011; 190(2): 148-154.

49. Basarslan F, Yilmaz N, Ates S, Ozgur T, Tutanc M, Motor VK, et al. Protective effects of thymoquinone on vancomycin-induced nephrotoxicity in rats. Hum Exp Toxicol. 2012; 31(7): 726-733. BY NC) license (https://creativecommons.org/licenses/by-nc/4.0/). 